\title{
РОЛЬ ИНТЕЛЛЕКТУАЛЬНЫХ РЕСУРСОВ В РАЗВИТИИ МАЛОГО БИЗНЕСА
}

\author{
(C) 2021 Иневатова Ольга Александровна \\ кандидат экономических наук \\ Оренбургский государственный университет, Россия, Оренбург \\ E-mail: inevatova.olga@mail.ru \\ (c) 2021 Иванова Юлия Александровна \\ Оренбургский государственный университет, Россия, Оренбург \\ E-mail: Yulia.ivanova080902@gmail.com \\ (c) 2021 Кичигина Айгуль Мансуровна \\ Кумертауский филиал Оренбургского государственного университета, Россия, Кумертау \\ E-mail: nurgaleeva_1994@mail.ru
}

Рассмотрены общие характеристики интеллектуального капитала, их влияние на сферу малого бизнеса. Интеллектуальный капитал рассмотрен в виде одного из основополагающих факторов, способствующих развитию малого бизнеса. Все утверждения, гипотезы, выводы основаны на статистических данных за прошедшие несколько лет, отражающих сущность и этапы развития интеллектуального капитала в современном мире.

Ключевые слова: интеллектуальный капитал, человеческие активы, малый бизнес.

В современном постиндустриальном обществе главное место занимают информация и знания, они проникают во все сферы общественной жизни. Для экономики интеллектуальные ресурсы становятся одной из основных черт, характеризующих ее как экономическую инфраструктуру. Малый бизнес играет одну из ключевых ролей в развитии современной экономики, он является основным источником налоговых сборов, создает рабочие места и выполняет множество других важных функций. Поэтому развитая и стабильная сфера малого бизнеса, благоприятно скажется на развитии экономики страны. А для стабильного роста и развития необходимо внедрять новые ресурсы, по другому, фирмам необходимо развивать и увеличивать интеллектуальный капитал своих организаций.

Актуальность: В последнее время в Российской Федерации большое внимание уделяется развитию малого бизнеса, так как расширение этой сферы, увеличивает количество налогов поступающих от нее, а это, в свою очередь, увеличивает бюджет страны. Для этого создаются специальные проекты по поддержке малого и среднего предпринимательства, ежегодно увеличивается количество субсидий и льгот малым предприятиям, проводятся другие стимулирующие политики. Сегодня информация и знания, как говорилось ранее, являются наиболее значимыми и важными ресурсами, играющими огромную роль в развитии бизнеса, государство и сами фирмы уделяют внимание внедре- нию интеллектуальных ресурсов в деятельность предприятий, так как это способствует эффективному развитию бизнеса, поэтому внедрение интеллектуального капитала является одной из актуальных проблем современной экономики.

Цель: выяснить роль интеллектуальных ресурсов в развитии малого бизнеса, выявить проблемы внедрения интеллектуального капитала в деятельность предприятий, конкретизировать пути решения проблем.

Для решения проблемы для начала стоит дать более полное определение понятию интеллектуального капитала, Т.Стюарт, в своей работе «Интеллектуальный капитал - новый источник богатства организации», определяет его как «интеллектуальный материал, включающий в себя знания, опыт, информацию, интеллектуальную собственность... Это - коллективная умственная энергия [4]. Современные экономисты определяют интеллектуальный капитал, как некую совокупность технических, гуманитарных, естественнонаучных сведений, которые могут быть задействованы с пользой в бизнесе. Другими словами, интеллектуальный капитал - это все знания и информация, которыми владеет та или иная компания и способна использовать их в своей деятельности. Владение, правильное управление этим ресурсом играет большую роль в будущих успехах фирмы, ее дальнейшем развитии, так как данный вид капитала - главное орудие фирм в современном мире, с его помощью можно решать различного рода управлен- 
ческие проблемы, максимизировать способность использования передовых технологий.

Основными компонентами, входящими в состав интеллектуального капитала являются нематериальные активы, а также интеллектуальная собственность. Согласно Положению по бухгалтерскому учету (ПБУ $14 / 2007)$ под нематериальными активами понимается объект, способный приносить организации экономические выгоды в будущем, объект, предназначенный для использования в производстве и оказании услуг для управленческих нужд [3]. Примерами нематериального актива могут стать различного рода изобретения, также товарные знаки и знаки отличия, секреты производства и т.д. Понятие интеллектуальной собственности определяется Гражданским кодексом РФ в ее состав входят произведения науки, литературы и искусства, базы данных, изобретения, фирменные наименования, коммерческие обозначения и т.д. [1].

Структуру интеллектуального капитала, по мнению Т.Стюарта и других современных экономистов, составляют:

- человеческий капитал;

- организационный капитал;

- потребительский капитал [4].

\section{Человеческий капитал.}

В это понятие определяется как некая совокупность знаний, умений, навыков, которые используются для удовлетворения различных потребностей фирмы [2] (расширение производства, повышение качества товаров и услуг, увели- чение прибыли и т.п.). Термин впервые использовался в 1958 году экономистом Джейкобом Минцером. Сегодня его зачастую определяют, как один из самых главных факторов, влияющих на формирование и развитие фирмы и экономики в целом. Человеческий капитал в рамках организации может постоянно менять свой объем, это связано в первую очередь с развитием личности сотрудника, увеличением или уменьшением количества персонала, а также, вследствие взаимодействия сотрудников с управляющим составом компании и другими компаниями, что отражает заинтересованность сотрудников в совершенствовании экономической деятельности фирмы и благоприятно сказывается на развитии предприятия. Человек может сам вкладывать средства и силы в развитие своих способностей или же это может сделать за него его компания, что способствует появлению у человека необходимых для деятельности фирмы качеств и способностей. Человеческий капитал неотделим от самого человека, поэтому сотрудники могут его использовать максимально эффективно, что позволит повысить конкурентоспособность своей фирмы или же наоборот, окажет противоположный эффект. Поэтому компании важно грамотно подойти к вопросам управления персоналом.

Для подтверждения значимости для компаний работников, обладающих уникальными навыками и способностями, продемонстрирован уровень заработной платы в различных профессиях по данным Минтруда РФ за 2019 год (рис. 1).

Из данных диаграммы мы видим, что в про-

\section{уровень 3П}

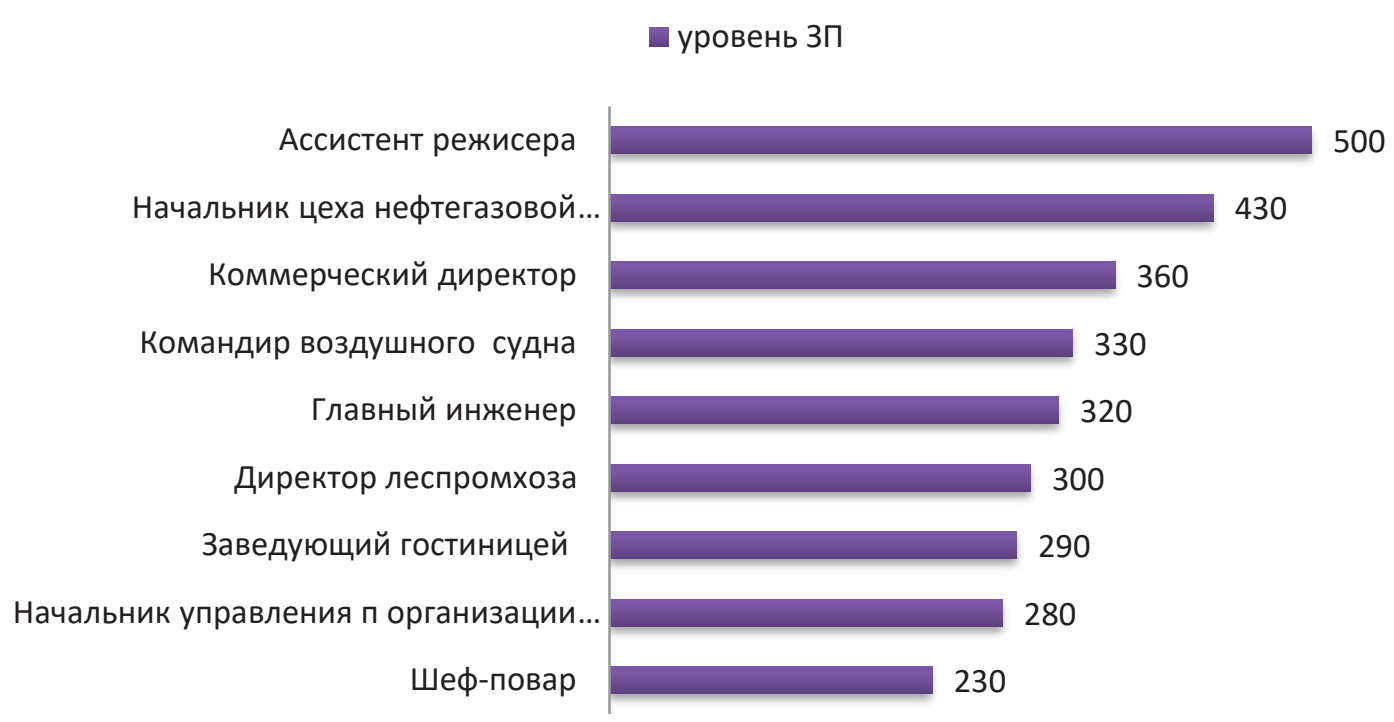

Puc. 1. Уровень заработной платы в различных отраслях и сферах деятельности [5] 
фессиях, где больше задействованы умственные, творческие способности работника, его навыки и опыт, заработная плата выше, это значит, что данные профессии и личные качества и способности работников представляют особое стратегическое значение для компаний, и они готовы платить им больше, чем другим работникам.

\section{Организационный капитал.}

Эта часть интеллектуального капитала, отличительная черта которого заключается в том, что он имеет непосредственное отношение к компании в целом, представляет собой совокупность организационных знаний, различных способов управления персоналом организации, культурой компании, а также патентов и интеллектуальной собственности, которой обладает фирма. Человеческий капитал имеет тесную связь с организационным капиталом, потому что он формируется и развивается, в первую очередь, под его воздействием. Для увеличения объема данного капитала, компания может самостоятельно, с помощью своих работников и их знаний разрабатывать различные технологии или же она может инвестировать в разработки стороннего предприятия, для использования их технологии в будущем. Многие фирмы выбирают именно этот путь, так как он может быть менее финансово затратным для них. Так, к примеру, только за 2017 год из бюджета предпринимательского сектора на исследования и разработки было выделено более 30\% от общего финансирования.
Статистика Росстата показывает, что с каждым годом удельный вес малых предприятий осуществляющих технологические инновации растет, увеличивается объем финансирования научных разработок. Для примера взяты данные по количеству малых предприятий по федеральным округам России за несколько последних лет (рисунок 2).

В разрезе отраслей по видам экономической деятельности в большинстве также наблюдается рост удельного веса предприятий, осуществляющих финансирование технологических инноваций.

Кроме инвестиций немаловажно с точки зрения организационного капитала уделять внимание развитию корпоративной культуры, так как она позволяет улучшить интеллектуальный капитал, имеющийся у компании, за счет совместной работы сотрудников. Корпоративная культура включает в себя различного рода нормы поведения для сотрудников, их взаимодействие, обмен знаниями, нормами и т.п. между работниками.

\section{Потребительский капитал.}

Последним компонентом интеллектуального капитала является потребительский капитал. Он представляет собой совокупность норм, способов взаимодействия фирмы с клиентами [6]. Объем данного капитала влияет на удовлетворение потребителей товарами и услугами, предоставляемых фирмой. К потребительскому

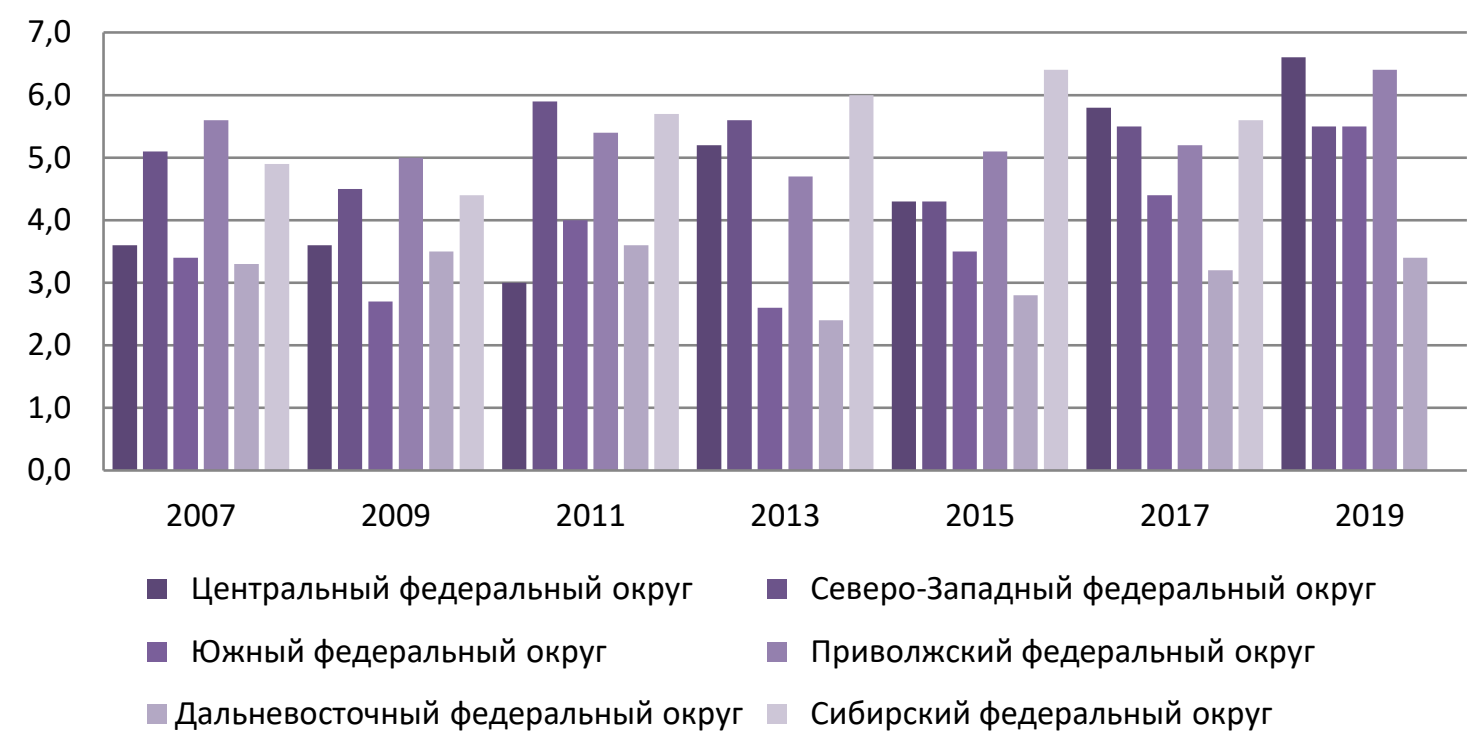

Puc. 2. Удельный вес малых предприятий, осуществлявших технологические инновации в разрезе федеральных округов РФ [5] 
Таблица 1. Удельный вес малых предприятий, осуществлявших технологические инновации по видам экономической деятельности [5]

\begin{tabular}{|l|c|c|c|c|c|c|c|}
\hline $\begin{array}{c}\text { Наименование вида экономической } \\
\text { деятельности }\end{array}$ & 2007 & 2009 & 2011 & 2013 & 2015 & 2017 & 2019 \\
\hline $\begin{array}{l}\text { Производство и распределение } \\
\text { электроэнергии, газа и воды }\end{array}$ & 1,6 & 1,8 & 3,1 & 2,2 & 2,2 & 3,4 & 2,9 \\
\hline Обрабатывающие производства & 4,5 & 4,3 & 5,4 & 5,1 & 4,8 & 5,8 & 6,6 \\
\hline Добыча полезных ископаемых & 3,5 & 3,1 & 3,4 & 3,1 & 2,8 & 2,4 & 2,0 \\
\hline Всего & 4,3 & 4,1 & 5,1 & 4,8 & 4,5 & 5,2 & 5,9 \\
\hline
\end{tabular}

капиталу можно отнести степень известности бренда фирмы, уровень ее сервиса, оказываемого покупателям, эффективность способов и путей взаимодействия с потребителями, их доступность. Размер прибыли, которую получит фирма, зависит от объема вышеперечисленных факторов. Потребительский капитал, может оказывать значительное влияние на итоговую прибыль компании, так, к примеру, размер прибыли «Яндекса» в их сегменте «Такси» в нынешнем году составляет 31\% от общей выручки компании, а число поездок увеличилось на 24\%, по сравнению с прошлым годом выручка сегмента составляет 45310 млрд.р., что на 46\% выше показателей прошлого года. Такой рост в первую очередь связан с тем, что компания улучшила свою систему взаимодействия с клиентами (создание единого приложения со всеми сервисами, удобная система отзывов и пожеланий), это повысило популярность данного сервиса, по сравнению с фирмами конкурентами. Данный пример хорошо иллюстрирует роль грамотной работы с клиентами и важность развития данного направления для компаний, желающих повысить свою прибыль.

Управление, использование, увеличение объема интеллектуального капитала.

Грамотное использование и управление интеллектуальным капиталом, играет большую роль в сохранении конкурентоспособности и увеличении прибыли фирмы, так как без хорошей системы управления часть капитала может простаивать и не использоваться, а объем прибыли не будет расти. Поэтому фирмы занятые сфере малого бизнеса в процессе внедрения в свою деятельность интеллектуального капитала, должны уделять этому вопросу особое внимание, так как иначе могут столкнуться с рядом проблем:

- невозможностью полного контроля над капиталом, из-за его неразрывности с сотруд- ником;

- истощение человеческого актива с течением времени;

- разницей в степени отдачи от капитала, зависящего от волеизъявления субъекта, его особенностей;

- неэффективное и не полное использование имеющегося интеллектуального капитала;

- значительными финансовыми затратами на увеличение и развитие интеллектуального капитала, из-за отсутствия грамотного плана.

Для избегания этих проблем, для максимально грамотного использования человеческих активов, в их максимальном объеме требуется эффективная система управления интеллектуальным капиталом, а значит, требуется хорошо организованное управление персоналом (область деятельности, направленная на обеспечение предприятия квалифицированным персоналом, способным выполнять возложенные на него трудовые функции [2]).

Для этого фирме необходимо, во-первых, сформировать свою собственную кадровую политику (совокупность целей и принципов, которые определяют направление и содержание работы с персоналом [6]), подходящую сфере деятельности компании и сотрудникам задействованных в ней. В этом фирмам может помочь выявление предметов управленческого труда, их особенностей и функций, с помощью этого людям, занятым в сфере управления, будет легче повысить эффективность своей деятельности.

Во-вторых, немаловажным является разработка и внедрение различного рода стратегий, способов мотивации персонала к труду на каждом уровне. Периодическое проведение различного рода мероприятий для персонала, повышающих их желание трудиться на благо предприятия, способствующих сплоченности коллектива.

Эти этапы повысят эффективность имеющегося интеллектуального капитала, без увеличе- 
ния его объема. Но со временем человеческие активы истощаются, для предотвращения этого необходимо настроить систему переобучения своих сотрудников, уделять достаточное внимание их отдыху и психологическому состоянию. Используя все эти методы при ведении бизнеса, фирма избавится от дополнительных расходов, которые могли возникнуть по причине отсутствия эффективной работы с сотрудниками и контролем над человеческими активами. Сохранившиеся ресурсы фирма сможет перенаправить на развитие других направлений деятельности, повышающих ее конкурентоспособность, а также способствующих увеличению будущего бюджета, а увеличение количества фирм с высокой прибылью в сфере малого бизнеса, окажет положительное влияние на развитие экономики страны в целом.

Заключение: В заключении стоит отметить, что со стремительным развитием мира, его со- вершенствованием, каждая компания, заинтересованная в успехе своей будущей деятельности должна уделять внимание развитию своего капитала, его увеличению. С каждым годом влияние и значение интеллектуального капитала только растет, повышается ценность нематериальных активов, поэтому фирмам малого и среднего бизнеса необходимо: совершенствовать свою систему внутреннего устройства, управления ресурсами, в особенности человеческими, так как они играют важную роль в формировании ее конкурентоспособности, известности, имиджа; уделять внимание развитию интеллектуальной собственности и потребительскому капиталу, подстраиваться под современные условия ведения бизнеса. Все это поможет обеспечить успех в их производственно-хозяйственной и экономической деятельности и благоприятно скажется на максимизации будущей собственной прибыли.

\section{Библиографический список}

1. Духнич Ю. Интеллектуальный капитал: составляющие, управление, оценка [Электронный pecypc] URL: http://www.cfin.ru/management/strategy/competit/Intellectual_Capital.shtml

2. Интеллектуальный капитал организации: понятия, структура, формы, виды, ресурсы, оценка, управление, развитие [Электронный ресурс] URL: https://businessman-ru.turbopages.org/businessman.ru/s/newintellektualnyj-kapital-organizacii-ponyatie-struktura-formy-vidy-resursy-ocenka-upravlenie-razvitie.html.

3. Положение по бухгалтерскому учету Учет нематериальных активов / ПБУ 14/2007.

4. Стюарт T. А. Интеллектуальный капитал. Новый источник богатства организации / Пер. с англ. - М. Поколение, 2007.- 12 с.

5. Федеральная служба государственной статистики [Электронный ресурс] URL: https://rosstat.gov.ru/

6. Хардон К. М. Молодчик М.А. Интеллектуальные ресурсы Российского малого бизнеса: прямое и косвенное влияние на результаты деятельности // Журнал экономические теории. - 2019.- Т.16. -№ 1.- С.75-90. 